University of Wollongong

Research Online

Faculty of Social Sciences - Papers (Archive) Faculty of Arts, Social Sciences \& Humanities

$1-1-2019$

\title{
The role of social cues in supporting students to overcome challenges in online multi-stage assignments
}

\author{
Tiffani L. Apps \\ University of Wollongong, tiffani@uow.edu.au \\ Karley A. Beckman \\ University of Wollongong, karleymc@uow.edu.au \\ Sue Bennett \\ University of Wollongong, sbennett@uow.edu.au \\ Barney Dalgarno \\ Charles Sturt University, bdalgarno@csu.edu.au \\ Gregor Kennedy \\ University of Melbourne, gek@unimelb.edu.au
}

See next page for additional authors

Follow this and additional works at: https://ro.uow.edu.au/sspapers

Part of the Education Commons, and the Social and Behavioral Sciences Commons

Research Online is the open access institutional repository for the University of Wollongong. For further information contact the UOW Library: research-pubs@uow.edu.au 


\title{
The role of social cues in supporting students to overcome challenges in online multi-stage assignments
}

\begin{abstract}
Online technologies can facilitate new assessment designs, where students develop, analyse and reflect upon their learning. Online multi-stage assignments provide students with opportunities to submit and share their work over an extended period in social sharing spaces such as blogging and discussion forums. This study explores the challenges experienced by students while completing online multi-stage assignments and the processes of self-regulated learning students engaged with to overcome such challenges. We present interview data from three qualitative case studies involving 34 students across two Australian universities. The results show all students experienced challenges while working on multistage assignments. Students engaged with both online and offline social cues to regulate their learning and overcome task challenges. We discuss the design implications and provide recommendations for further research.

Disciplines

Education | Social and Behavioral Sciences

\section{Publication Details}

Apps, T., Beckman, K., Bennett, S., Dalgarno, B., Kennedy, G. \& Lockyer, L. (2019). The role of social cues in supporting students to overcome challenges in online multi-stage assignments. The Internet and Higher Education, 42 25-33.
\end{abstract}

\section{Authors}

Tiffani L. Apps, Karley A. Beckman, Sue Bennett, Barney Dalgarno, Gregor Kennedy, and Lori Lockyer 
Title: The role of social cues in supporting students to overcome challenges in online multi-stage assignments

\begin{abstract}
Online technologies can facilitate new assessment designs, where students develop, analyse and reflect upon their learning. Online multi-stage assignments provide students with opportunities to submit and share their work over an extended period in social sharing spaces such as blogging and discussion forums. This study explores the challenges experienced by students while completing online multi-stage assignments and the processes of self-regulated learning students engaged with to overcome such challenges. We present interview data from three qualitative case studies involving 34 students across two Australian universities. The results show all students experienced challenges while working on multi-stage assignments. Students engaged with both online and offline social cues to regulate their learning and overcome task challenges. We discuss the design implications and provide recommendations for further research.
\end{abstract}

\title{
Keywords
}

Self-regulated learning, online assessment, social models, social cues 


\section{Introduction}

Student-centered assessment tasks are designed to support learners to construct knowledge through task engagement and require students to more independently manage and self-regulate their learning. This occurs as students are expected to: interpret the task requirements to create their own understanding of the teacher set task; decide on what approach to take and set their own goals; choose effective strategies and monitor their progress; and make any necessary adaptations while completing the task. At any of these stages, students can experience challenges, which they need to overcome to be successful. The mark of self-regulated learning (SRL) is that strategic processes are activated, monitored, evaluated and controlled when there is a real need to do so, such as when a challenge is encountered. Yet, there is a paucity of research that explores SRL when students experience challenges (Zimmerman \& Schunk, 2011).

Online technologies can provide new ways for assessment to be more socially supported. Contemporary assessment designs that focus on "assessment for learning" rather than "assessment of learning" can provide students with opportunities to develop their responses iteratively over time (Boud, 2000). For example, through blogging or journaling their ideas in online spaces shared with other students. This type of online multi-stage design provides new opportunities for students to seek support and assistance to address the challenges they may experience. Despite these new opportunities, we know relatively little about how students experience online multi-stage assessment designs. Greater understanding would assist with practical challenges associated with online design and at the same time add important new detail to understanding learning and assessment in higher education.

The study presented in this paper examines the role of social cues in assisting students to regulate their learning to address challenges while completing multi-stage assignments online. We use the term social cue to describe the resources accessed by students when faced with a challenge within the teaching and learning environment. The following section presents a brief overview of the body of research focused on SRL in higher education. Findings from three case studies are presented. We detail the challenges students experienced while completing online multi-stage assignments, paying attention to the role of social cues in supporting students to address difficulties and work towards task completion.

\section{Background}

Self-regulated learning describes the processes whereby students activate and sustain cognition, affects, and behaviours that are systematically oriented toward the attainment of personal goals (Zimmerman \& Schunk, 2011). With adult learners, SRL occurs across three basic domains: cognitive/metacognitive, motivational and social/environmental. Models of SRL, proposed 20 years ago, focused on student directed study sessions. At this time in higher education students would attend teacher directed lectures and tutorial, workshop or lab classes. Studying was generally focused on reviewing content in 
preparation for exam-based assessment. Within this context SRL research has focused on measuring aspects of students' regulation during study and recall sessions. For example, metacognitive monitoring studies concerned with measuring students' relative accuracy, calibration or metacomprehension (Winne, 2011).

In contemporary Australian universities teaching and learning takes a more studentcentred approach. Students attend face-to-face and/or online classes and assessment of learning is more likely to consist of student-centred tasks such as: problem-based learning (Jonassen \& Kim, 2010; Kim \& Hannafin, 2011); authentic learning (Herrington, Reeves, Oliver, \& Woo, 2004); and online collaboration (Laurillard, 2009; Lockyer, Patterson, \& Harper, 2001). Within this context much of students' 'self-directed' study is contextualised within a particular learning environment and focused on a teacher designed assessment task. This shift in higher education provides opportunities to extend our understanding of the processes of SRL beyond traditional study sessions to studentcentred tasks in online environments.

Thus, the role of the social context in self-regulation has evolved over the last 20 years. While early models depicted SRL as an individual, cognitive-constructive activity (Hadwin, Oshige, Gress, \& Winne, 2010), contemporary socio-cognitive models of SRL emphasise the social context and learning environment that frame conditions of learning (Hadwin \& Oshige, 2011; Schunck, 2001). In this way, SRL involves personal perceptions and efficacy, as well as environmental conditions such as support from teachers and feedback when engaging with assessments for learning. Social processes that are highlighted in socio-cognitive models of regulation include feedback, learner control of the task and challenge(s), modelling, and different levels of scaffolded support (Hadwin \& Oshige, 2011).

Although technology adds new complexity to university learning, online learning can afford opportunities to develop unique open-ended assessments for learning. One example is a multi-stage assignment completed by students in a discussion space within a learning management system (LMS). Such tasks provide students opportunities to 'practice', monitor, share and review work during the task period, all of which are cognitive and metacognitive processes of SRL. Case study research investigating the self-regulation of six students in a web-based blogging course has found that characteristics of the online environment played a significant role in facilitating students' help seeking and monitoring (Whipp \& Chiarelli, 2004). These findings highlight the potential of online multi-stage task design, like blogging, to support SRL.

This study is framed by Winne and Hadwin's cognitive model, which depicts SRL as four loosely sequenced recursive phases: defining the task, setting goals and planning; engagement; and large-scale adaptation (Winne, 2011; Winne \& Hadwin, 1998). When a student faces a challenge at any phase, opportunities arise for self-regulation, through monitoring, evaluation and control, to address difficulties and successfully complete the task. Research exploring students' monitoring when challenged has focused on studying 
and re-studying for exam-based assessment (Kornell \& Bjork, 2007; Winne, 2011). Contemporary SRL studies in higher education have moved from a focus on traditional study for exam-based assessment to open ended-tasks in online environments, such as reflective journal, ePortfolios and project-based learning (Cheng \& Chau, 2013; English $\&$ Kitsantas, 2013; Lin, 2018). The study presented in this paper makes a novel contribution to this research through an examination of the challenges experienced by students while completing online multi-stage assignments and the social cues students engaged with to regulate their learning and overcome such challenges.

We present data from three cases that involved blogging style or journaling online tasks as examples of multi-stage assignments. The study aimed to investigate students' SRL when faced with a challenge in this context. We pay particular attention to the role of social cues that may support students through such challenges.

\section{Method}

The paper presents data from three embedded cases from two Australian universities (regional and metropolitan). The cases were selected based on the inclusion of a multistage student-centred online assessment design, hereafter referred to as multi-stage assignment. The three cases involved face-to-face subject delivery encompassing traditional lecture and tutorial formats. Each multi-stage assignment required students to respond to subject materials in an online space. All were reiterative providing students the opportunity to complete postings or journal style response at a number of intervals throughout the semester. The assignments in Cases A and B were shared in online discussion forums that could be viewed by all students in the case. While the assignment in Case $\mathrm{C}$ was an individual online journal that could only be accessed by the student and their tutor.

The social context explored in this study included online and offline learning spaces and networks, in which students operated to complete the multistage assignment. A brief contextual description of each case follows.

\subsection{Case A}

Case A (metropolitan university) was a Culture and Communication undergraduate subject designed to provide an overview of cultural studies approaches to contemporary popular music. The multi-stage assignment was a blogging task that required students to respond to weekly prompts in relation to the subject content and readings. Weekly prompts focused on a cultural analysis of contemporary popular music. For example:

Artists use a range of promotional tools to develop their brands. Often selfpromotion can be humorous, ironic, self-deprecating, or otherwise 'reflexive' in relation to the music industry and commercial motives. Find an original, daring or surprising promotional strategy by a popular music 
artist and explain how the promotion works to brand the artist (blog prompt

2, subject LMS).

Students were required to submit a minimum of eight 150 -word posts in response to weekly blog prompts over the semester. Students could view others' blog posts in the shared space, however, were not required to engage with their peers' posts. Students were encouraged to write in a creative conversational style and include multimedia. The teaching team provided informal written feedback on students' first blog post. The aim of the assignment was to provide an opportunity for students to develop their ideas for the following essay assignment.

\subsection{Case B}

Case B (regional university) was a History undergraduate subject designed to explore historical events through film. The multi-stage assignment was an online postings task designed to foster critical engagement with the varied ways history is represented in film. Each post was a critical commentary to the weekly study materials, which included a film, associated readings and a lecture. Students were required to post eight 300 -word critical commentaries to an online discussion forum, at allocated times throughout the semester. Students were encouraged to think critically and move beyond summarising content. For example the task description described,

Commentary means more than a summary of content. Respond to the material, the arguments put, the reasons for the argument and/or what might puzzle you (subject outline).

Students could view others' posts in the shared space and could comment, however, this was not a requirement. General informal feedback was provided in class discussions. The assignment was marked at the end of the semester as one product.

\subsection{Case C}

Case C (regional university) was a Humanities and Social Inquiry undergraduate subject designed to investigate the impact of punishment on society. The multi-stage assignment was a reflective journal that included three 500-word entries, over three weeks. In each entry students responded to weekly focus questions focused on punishment and society. The questions were designed to encourage independent thinking and allowed students to write in a personal and reflective style. For example the task description described,

List four aspects of the criminal justice system, courts, prisoners, crime that you already know from different sources especially from the media. Having read the Sarre article how has it altered or not altered your ideas? (subject outline).

Students had the option to submit a draft of each week's journal entry as a private online post in the LMS (other students could not view). Then students compiled and submitted the three journal entries in one document at the completion of the assignment period. No general feedback was provided on student progress during the task period, however, the class discussions aligned with the assignment content, thus allowing opportunity for self- 
monitoring and evaluation. The task was marked midway through semester as one product.

\subsection{Data collection and analysis}

Each case study consisted of two units of analysis including: (1) all students and teachers within the case and (2) a smaller number of randomly selected individual students. This paper will present semi-structured interview data from the second unit of analysis: 34 individual students (Case $A=7$, Case $B=16$, Case $C=11$ ), hereafter referred to as students. Students were interviewed two times: 1) After receiving information through the subject outline and initial lectures, but prior to commencing the task; and 2) after engaging in one or more stages of the task. Student interviews focussed on general study practices, perceptions of the subject including the online environment, understanding of the multi-stage assignment and how they went about working on the assignment including plans, strategies, challenges, adaptations and reflections.

All students participated in the study with informed consent and were free to withdraw participation at any time. Student interviews were recorded and transcribed verbatim for analysis with qualitative analysis software. During the first stage of analysis, the research team organised data from one case into key interview categories to allow for the identification of emerging codes. These codes formed the foundation of the preliminary coding framework, which identified each code along with illustrative examples from interview transcripts. Three members of the research team applied these codes independently and coding was compared to locate discrepancies. Differences were discussed and resolved by the team, which was reflected in the framework. The second stage of analysis focused on the application of selected codes to three cases including 68 transcripts from the 34 participating students. Student challenges, monitoring and adaptations were coded according to framework, as well as inductively based on emerging themes. Inductive codes were collated in a spreadsheet together with a detailed code description and example. Once all members reached consensus, emergent codes were then reviewed by the research team and added to the coding framework. 


\section{Findings}

\subsection{Challenges}

All students (34) described experiencing challenge(s) while engaging in the multi-stage assignment. Analysis of interview data across the three cases revealed that $15 \%(5 / 34)$ of students experienced one challenge while completing their assignment, 38\% (13/34) experienced two challenges, and 47\% (16/34) of the students experienced three or more challenges.

Six major categories were identified during analysis of students' assignment challenges including: knowledge of the task, domain knowledge, monitoring progress, time management, motivational factors and the teaching and learning environment. Table 1 presents the challenges experienced by students, aligned with Winne and Hadwin's model of SRL (1998). Students adopted a range of strategies to overcome these challenges, including social support strategies. The following section describes the social support strategies adopted by students in relation to these challenges. 
Table 1 Challenges experienced by students while engaging in multi-stage assignments

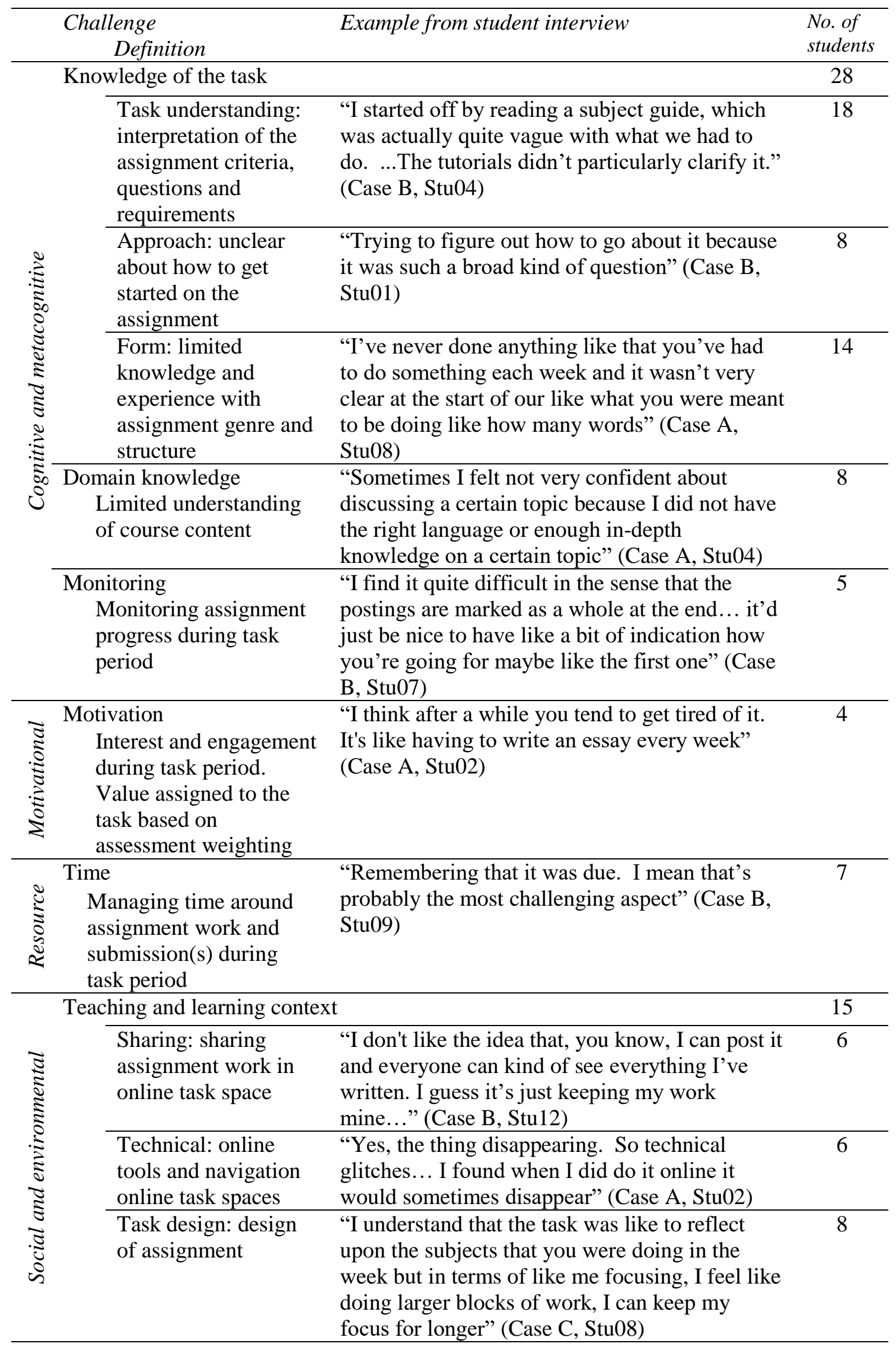




\subsection{Social cues as a support to address challenges}

Students described a range of strategies to address task challenges, including using social cues. Overall, 27 from 34 students (79\%) applied 45 social cues. Five students from Case A applied a total of 10 social cues. Fourteen students from Case B applied 26 social cues and eight students from Case $\mathrm{C}$ applied nine social cues to overcome challenges. In all cases the multi-stage assignments facilitated opportunities for students to make external evaluations, update task understanding and work towards addressing challenges at various stages while engaging with the assignment. In all cases the social context of the multistage assignments included the online and offline learning environments that students operated in to complete their assignments. Students monitored their understanding and progress within the social context of the multi-stage assignments using a range of social cues such as social models, tutor feedback, engaging with peers and class discussions. These social cues are described below in Table 2. Table 2 also presents the number of student references to social cues applied to overcome challenges for each case.

Table 2 Social cues supporting students' self-regulation when faced with a challenge

\begin{tabular}{llcccc}
\hline Social cue & Description & $\begin{array}{c}\text { Case } \\
\text { A(5) }\end{array}$ & $\begin{array}{c}\text { Case B } \\
(14)\end{array}$ & $\begin{array}{c}\text { Case } \\
\text { C (8) }\end{array}$ & $\begin{array}{c}\text { No. students } \\
\text { across cases } \\
\text { (27) }\end{array}$ \\
\hline Social models & $\begin{array}{l}\text { Viewed other students' work } \\
\text { in the LMS as a 'coping } \\
\text { model' or exemplar }\end{array}$ & 5 & 11 & $\mathrm{n} / \mathrm{a}$ & 16 \\
\hline $\begin{array}{l}\text { Tutor } \\
\text { feedback }\end{array}$ & $\begin{array}{l}\text { General feedback provided } \\
\text { to students in relation to their } \\
\text { task progress }\end{array}$ & 3 & 7 & 4 & 14 \\
\hline Class discussion & General class discussions & 1 & 6 & 1 & 8 \\
\hline Peer discussion & $\begin{array}{l}\text { Discussions with peers in } \\
\text { relation to the task }\end{array}$ & 1 & 2 & 4 & 7 \\
\hline Student references to social cues & 10 & 26 & 9 & 45 \\
\hline
\end{tabular}

Table 3 outlines student references to social cues, across cases, which were adopted in response to specific challenges reported by students (see Table 1). Twenty-seven of the 34 students who described challenges applied a social cue to address those challenges. The total number of student references to social cues presented in the table exceeds the number of students applying cues across the cases, as 21/27 (78\%) students applied social cues to overcome multiple challenges. Table 3 demonstrates that social cues supported students with challenges associated with knowledge of the task, domain knowledge, monitoring progress and the teaching and learning context. In line with the focus of this paper, the findings presented in the following sections will explore the social cues adopted by students to address these challenges. Time and motivational challenges have been excluded, as students did not discuss the application of social cues in response to these challenges. A discussion of each social cue that supported students' self-regulation when faced with a challenge follows. 
Table 3 Overview of the social cues used to address challenges

\begin{tabular}{|c|c|c|c|c|}
\hline \multirow[b]{2}{*}{ Challenges } & \multicolumn{4}{|c|}{ Social cues } \\
\hline & $\begin{array}{l}\text { Social } \\
\text { models }\end{array}$ & $\begin{array}{c}\text { Tutor } \\
\text { feedback }\end{array}$ & $\begin{array}{c}\text { Class } \\
\text { discussion }\end{array}$ & $\begin{array}{c}\text { Peer } \\
\text { discussion }\end{array}$ \\
\hline No. of students & $(16)$ & (14) & (8) & (7) \\
\hline \multicolumn{5}{|l|}{ Knowledge of the task } \\
\hline Task understanding & 11 & 8 & 6 & 3 \\
\hline Approach & 5 & 2 & 0 & 2 \\
\hline Form & 7 & 4 & 4 & 4 \\
\hline Domain knowledge & 5 & 4 & 1 & 2 \\
\hline Monitoring & 3 & 1 & 2 & 0 \\
\hline Teaching and learning context & 3 & 0 & 1 & 0 \\
\hline $\begin{array}{l}\text { Total number of student referer } \\
\text { social cues used to overcome } \\
\text { challenges }\end{array}$ & 34 & 19 & 14 & 11 \\
\hline
\end{tabular}

\subsection{Social models}

Students described viewing other students' work in the online space as a model. We refer to this process as a social model as it occurred in the online social context of the task. Cases A and B involved students posting their work each week to a shared space on the subject LMS, visible to all students enrolled in the course. Students from Case C were unable to view other students' work, and thus did not discuss social models as a support strategy. Sixteen students, 5 from Case A and 11 from Case B, described viewing their peers' posts as a social model. This strategic process supported students to work through challenges related to knowledge of the task, domain knowledge, monitoring progress and working in the teaching and learning context, discussed below.

\subsubsection{Social models and knowledge of the task challenges}

Fifteen students viewed other students' blog posts as a strategic process to overcome challenges associated with knowledge of the task (Case $A=4$ and Case $B=11$ ). Eleven of these students viewed other students' posts to formulate or clarify their task understanding, as two students described:

I've only really done it like twice or three times; one of them was to figure out what the hell was going on in the first half like with the two postings and like everyone was doing different things so it was no help. I was like "Goddam..." (Case B, Stu05).

I also read other peoples' blogs for that week because I was always doing them behind and that gave me some idea of what other people were thinking it was asking for (Case A, Stu08).

The open-ended nature of the multi-stage assignments presented a challenge for students. Five students described viewing posts in the shared space to get a sense of how others were approaching the assignments. Additionally, for many students this was their first experience writing in the form of a blog post for a university assignment. Students described this lack of experience with the form as challenging because it was vastly 
different to the more structured essay format with which they were accustomed. Viewing other students' posts as a coping model was a strategic process described by seven students that allowed for a more complete understanding of the task form. For example, one student described, "Before this subject I had no idea what a blog post was. I struggled in the first one because I had no idea until I saw other blog posts and I thought okay that's what I'll do" (Case A, Stu05).

\subsubsection{Social models and domain knowledge challenges}

Five students, who identified lack of domain knowledge as a challenge, read their peers' posts to clarify key ideas about the unit content and materials.

Usually if the reading is challenging and Wikipedia doesn't provide an adequate response or I'm getting stuck, I'll usually have a look at student responses to see what they've interpreted and see "Oh, okay, one student's interpreted that way, the other student's interpreted that way. This is what the author is saying”. That usually helps (Case B, Stu02).

So far, it's just lack of technical musical knowledge because there are some terminologies that's thrown around that I don't quite understand. ...I found reading other's blogs really useful (Case A, Stu03).

\subsubsection{Social models and monitoring challenges}

Three students from Case B used social models to evaluate their own posts against their peers as a strategy for monitoring progress. One student described relying on this strategy early on in the task and then decreasing this reliance as they progressed through the task period and their confidence grew.

I did read a few of them while doing the assessment early on to see what other people were doing, to see what track I was on... ...but the further I've gone in the semester, the more confident I've become in what I'm writing and just going along with what I'm going with (Case B, Stu06).

\subsubsection{Social models and teaching and learning context challenges}

Three students discussed sharing assignment work with peers as a challenge associated with the online learning environment (Case $A=1$; Case $B=2$ ); feeling apprehensive or confronted with the idea that other students could view their work and make judgments. Of these students two described the process of engaging in the online task space as significant in overcoming this challenge. For example, one student who initially described feeling confronted by the shared nature of the assignment described how engaging with the assignment and viewing other students' work allowed her to approach the task with increased confidence.

Yeah, well it frees you up to do that; it's like an invitation for me, "There you go. You can give us your opinion". "Oh yay". And it's good in the development of personality and confidence as a human being within the culture because you're able to establish what you think in contrast to what everybody is telling you to think (Case A, Stul6). 


\subsection{Tutor feedback}

Fourteen students used general feedback from the tutor (face-to-face and online feedback) to work through challenges associated with task knowledge, monitoring task progress and the teaching and learning context.

\subsubsection{Tutor feedback and knowledge of the task challenges}

Eleven students applied tutor feedback as a strategic process to overcome challenges associated with their knowledge of the task (Case $A=3$, Case $B=7$ and Case $C=4$ ). Of these students eight applied tutor feedback to work through challenges related to their task understanding. Five students from Case B applied feedback from the tutor in class to clarify task expectations following their first post. In this case, the tutors provided examples during face-to face class to assist students to compose their posts and engage with content at a higher level. Three of these students discussed adopting the example as a strategy to scaffold thinking and writing.

But she did say why didn't we make connections with the reading and the Ferguson riots that were happening. And that was my first kind of thing going "Okay, well I can make connections with it" ... By making a connection with the reading in something today I found like I can understand it a little bit more (Case B, Stu06).

By contrast, all students in Case A received individual feedback on their first blog posts. One student described this as useful in clarifying task understanding:

I think the first blogging task I was pretty apprehensive and I felt like it wasn't really as clear as I would have liked it to have been. ...Everyone's blog in week 3 was commented on - I received positive feedback then and tried to improve upon what I had already done in those first three week (Case A, Stu12).

Two students from Case B applied feedback from the tutor to work through challenges related to approaching the task. No other students described engaging with tutor feedback as a strategic process as to overcome difficulty starting the task. Four students applied tutor feedback to work through challenges related to understanding the task form.

\subsubsection{Tutor feedback and domain knowledge challenges}

Four students (Case $A=2$, Case $C=2$ ) engaged with tutor feedback when challenged by limited domain knowledge. In these cases the feedback worked to foster students' confidence about their developing knowledge. For example, "The feedback that team gave me was for the first blog post was positive. It gave me a confidence boost to write the rest of my blog posts" (Case A, Stu5).

\subsubsection{Tutor feedback and monitoring challenges}

One Case B student also strategically engaged with feedback provided in class to overcome challenges associated with monitoring their own progress, specifically, the absence of individual feedback on blog posts. In this regard the general tutorial feedback the student received was particularly important in facilitating metacognitive monitoring, for example: 
After the first posting, [the tutor] mentioned that the postings weren't about reiterating everything kind of thing, it wasn't like a recount. ...but I definitely think when [the tutor] mentioned in class the other time I think, not just myself but a lot of people in the class were actually like "Oh, okay that's what we're meant to be doing" (Case B, Stu07).

\subsection{Class discussion}

Eight students described strategically engaging in class discussions to address challenges associated with task understanding (6), task form (4), domain knowledge (1), monitoring progress (2), and the online task format (1). Class discussion that aligned with the task provided students with clearer understanding of the task and content knowledge:

Some weeks I did not quite understand the topic or I did not find the topic relevant to me or if it was really hard to find an example. ...Sometimes I would ask [the tutor] in class to explain something again or sometimes just in class through discussion it made more sense afterwards (Case A, Stu03).

Five of the six students who drew on class discussions to evaluate and refine their task understanding, were from Case B. In this case the tutorial activities intentionally mirrored the expectations of the assignment task. Three students relied on class discussions to clarify: understanding of content (1); the processes required to use the blog function in the LMS (1); and monitor progress (1) in lieu of personal feedback on the blog posts. In addition, four of the six students (Case B) also engaged with the cue to understand the task form as they had not previously engaged in an online multi-stage task.

\subsection{Peers}

Seven students engaged in face-to-face discussion with peers to support challenges associated with knowledge of the task (7) and domain knowledge (2). Seven students described engaging with peers, asking questions and sharing work, to address knowledge of task challenges including difficulty understanding task requirements, form and approach. For example:

I did not feel super-confident about that last question but I did get some of my friends who kind of understood the question to also read my answer to see if they think it answers the question and they said "yes" (Case C, Stu03).

Four of these students came from Case $\mathrm{C}$. A distinguishing characteristic of the Case $\mathrm{C}$ task was that students were unable to view their peers' work in the online learning environment. Without online social cues to monitor and refine understanding and standards these students relied on offline social supports and help-seeking described in models of SRL. Two students described discussing subject content with peers to clarify ideas when challenged by domain knowledge, for example: "this [talking to peers] reaffirmed what I thought. It was just like 'Oh, okay, yes so we are all on the same sort of page"” (Case C, Stu10). 
In sum, all students described experiencing challenges while completing the online multistage assignments. Challenges associated with knowledge of the task were most

frequently described. Students described some variation in the way that their lack of task knowledge manifested into challenges including understanding task, approaching task and understanding task form. Students strategically engaged with a range of social cues, online and offline, demonstrating self-regulation in efforts to overcome challenges and complete multi-stage assignments. 


\section{Discussion}

The aim of this study was to understand the role of the social context in supporting students' SRL while completing multi-stage online assignments. An examination of students' SRL in context of the challenges they experienced was conducted, as challenges provide a meaningful catalyst for metacognition. The following section presents a discussion of the challenges students experienced followed by the social cues that supported students' self-regulation while working to address these challenges. The challenges and social cues identified have important implications for the effective design of online assessments that support students and promote self-regulation.

\subsection{Challenges}

All students (34) experienced challenges while completing the multi-stage online assignments. Analysis of interview data revealed challenges associated with knowledge of the task, domain knowledge, motivation, time management, self-monitoring, and the teaching and learning context. A discussion of the major categories of challenges (Table 1) in context of the cognitive-metacognitive and social-environmental domains of selfregulated learning follows.

\subsubsection{Cognitive/metacognitive challenges}

Cognitive-metacognitive processes of SRL are used to monitor the process of cognition for their effectiveness and the amount of effort used (Zimmerman \& Schunk, 2011).

Analysis of student interviews revealed that students' knowledge of the task was the most common cognitive-metacognitive challenge experienced while completing the multi-stage assignment. Research suggests that task interpretation is a difficult process for students (Butler \& Cartier, 2004; Oshige, 2009; Rivera-Reyes, Lawanto, \& Pate, 2017). The findings of this study supported the literature, but also highlighted the added challenges of understanding the form of the academic blog or discussion post and confusion about how to approach the task. The cases selected for this study all included an online studentcentred multi-stage assignment. Although each assignment was grounded in distinctly different content knowledge, the common purpose of their design was to afford students an open-ended space to rehearse critical thinking in context of subject materials and aims. This type of assignment departs from more formal academic writing forms such as essays or reports, generally experienced by students. Our findings suggest the open-nature of the assignments (including both task design and descriptions) together with students' lack of experience with the style of writing contributed to this key challenge. Similarly, research investigating undergraduate students' task understanding and academic performance found that students experience more difficulty interpreting less prescriptive tasks (Oshige, 2009). While it is beyond the scope of this paper to analyse the task descriptions and instructions provided the findings suggest that the open-ended nature of the multistage assignments presented a challenge to their task understanding. The large proportion of students (28/34) that experienced challenges associated with task understanding suggests implications for how educators explain online multi-stage assignments in both formal written descriptions and informal instructions. 
Eight of the 34 students described cognitive-metacognitive challenges associated with domain knowledge while completing the multi-stage assignments. Given the acquisition of domain specific content knowledge is a central focus of university learning, the relatively small number of students describing domain knowledge challenges was surprising. One possible explanation for such a finding relates to the large portion of students who experienced challenges associated with their knowledge of the task. Studies have shown that task understanding is central in executing SRL strategies and achieving academic success (Oshige, 2009; Winne \& Hadwin, 1998). Thus, a clear understanding of the task parameters, genre and form, including appropriate strategies to approach the task, is first essential for students to then be able to engage deeply with subject content (or domain knowledge).

In addition, five of the 34 students described cognitive-metacognitive challenges associated with monitoring progress. This finding shows that these students were attempting to engage in metacognitive processes to make evaluations about their work across the multi-stage assignment period. However, these students found this process difficult without formal feedback. This finding suggests that in online multi-stage task design, where students engage in multiple iterations of a task across an extended period, formative feedback could better support students' self-regulation. Similarly, researchers have postulated that offering formative feedback at a sub-task level can support regulation during production affording students the space to act upon feedback (Nicol \& MacfarlaneDick, 2006).

\subsubsection{Social-environmental challenges}

The social-environmental domain of SRL focuses on the social context within which teaching and learning occurs (Zimmerman \& Schunk, 2011). Fifteen of the 34 students experienced social-environmental challenges associated with the teaching and learning context. Technical challenges associated with the learning environment illustrate the layer of complexity technology can add to a task. As well as students' need for support when engaging with new technology mediated assessment forms, such as the multi-stage assignment. Challenges were both technical and design related, including functional issues with LMS, the assignment design and concerns about sharing work with peers in the online space (Table 1). These functional issues highlight the layer of complexity the online environment can add to a task.

Students described a number of difficulties with aspects of the task design. Challenges associated with task design varied between cases. Task design challenges included: the absence of peer engagement as a requirement (Case A); timing of submission in relation to face-to-face tutorials, availability of course materials online and sharing work with peers in the online space (Case B); and the inclusion of multiple submission options (Case C). While students from each case described different challenges related to task design, collectively such challenges highlight aspects of the online multi-stage assignment design that might better support students. For example, a clear and necessary purpose to features 
of the online task space, increased accessibility to resources, the consideration of social support in task design and connection to face to face learning.

\subsection{Social context as a support for students' regulation}

When faced with challenges all students engaged with the social context of the multistage assignment to overcome difficulties. Differences in the social context existed between cases based on task design. For students from Cases A and B the social context of the task included both online and offline spaces, as they shared their assignment work in an open blog space within the LMS. For Case C students, the boundaries of this context differed as assignment work was not shared online with peers, thus limiting formal online social interaction and support. A discussion of the online and offline social cues students engaged with to overcome challenges along with the challenges students faced that were not supported by social cues follows.

\subsubsection{Online social cues}

The findings of this study demonstrated that students engaged with social models and feedback online to overcome challenges. The shared nature of the multi-stage assignments in Case A and B facilitated a space where students could view their peers work and, while not a requirement, contribute to their peers' ideas. Like Whipp \& Chiarelli (2004), this study found that viewing peers' posts provided students with a social model or worked example. Our findings show that students applied these social models to address challenges associated with task understanding, monitoring progress, teaching and learning context and domain knowledge. For many students the models provided a procedural knowledge, which allowed them to move past challenges to focus their working memory on the synthesis of ideas. In this way the models were used as a cognitive tool. Cognitive load theorists describe such a process as the worked example effect where students use a worked example to reduce cognitive load, freeing working memory capacity to focus on the synthesis of ideas (Sweller, 2016). Similarly, social cognitive models of SRL conceptualise the notion of supporting learners to develop academic competence with social models. Social modelling studies postulate that information shared socially can be internalised by students and used in self-regulation (Schunck \& Zimmerman, 2003).

The multi-stage assignment was shared with other students in the online space in both Cases A and B. Case A students received feedback from the tutor online early in the task period, while Case B students received no online feedback. Three of the five students in Case A who engaged with social cues to overcome challenges used the online tutor feedback. When compared with Case B students, who exclusively described challenges associated with monitoring progress, this finding suggests that formal task feedback early on in a multi-stage assignment might play an important role in promoting self-regulation and confidence across the task period. This supports findings by Brown, Peterson and Yao (2016), that providing students with early feedback is crucial in guiding subsequent learning, increasing SRL and academic performance. 
Our findings suggest the online task space promoted students' self-regulation via the provision of social models and formative feedback. These social cues allowed students to monitor, evaluate, refine understanding and adopt strategies. Social models played a particularly important role in supporting students' self-regulation as students most frequently engaged with others work to refine knowledge of the task, clarify domain knowledge, monitor progress and address challenges associated with the online learning environment.

\subsubsection{Offline social cues}

In addition to online social support, Case A and B students engaged with offline social cues, including tutor feedback in class, as well as class and peer discussions to overcome their challenges. Most students that described engaging with class discussions to overcome challenges came from Case B. In this context, the learning design was important as the face-to-face tutorials were structured in a similar format to the multistage assignment. Students discussed the weekly content in context of the subject aims and current events to draw parallels and scaffold thinking. Students in this case were provided tutor feedback early on that highlighted this scaffold that could be applied to their discussion posting task. This finding suggests that in this case the face-to-face tutorials were well connected to the online task, providing students with a transparency around the task and a variety of social cues to support their learning across spaces.

By contrast, the Case $\mathrm{C}$ assignment was designed for students to complete individually and submit directly to the tutor, without any opportunity to share task work. Students had the choice to upload their work to a private space within the LMS at each stage of the task or submit journal components as one task at the end of the task period. While the multistage nature of the task allowed for self-modelling or reflection at each stage of the task, these students lacked the social modeling supports afforded by the shared online space, as in Cases A and B. Without access to peers' work as a social cue, Case C students relied solely on class discussion, tutor feedback or peer discussion as social cues to overcome challenges. Eight of the eleven students in this case engaged with social cues in an attempt to overcome challenges associated with task understanding, domain knowledge and monitoring progress. Specifically, half of these students engaged with peers as a social support. Similarly, research suggests that undergraduate students are more likely to seek help from informal sources, like peers (Karabenick \& Knapp, 1991). The students in this case also drew on more formal social cues within face-to-face classes, or tutor feedback during individual consultation.

In all three cases a key aspect of these face-to-face social supports was the alignment of class discussions and tutor feedback with the assignment content and timing. Listening to the tutor and peers discuss subject materials, related to the weekly assignment content provided the opportunity for students to evaluate their understanding of the assignment and the subject materials to monitor their progress. Such processes resulted in a coregulation of learning, whereby the subject coordinators and tutors supported students' regulation through connected learning design and responsive scaffolding throughout the 
task period. In this social context the multi-stage design also facilitated co-regulation affording students' opportunities to enact feedback and support during production. As Hadwin and Oshige (2011) explain, co-regulation is a transitional process, between student and teacher, during which the learner gradually appropriates SRL.

Overall, the findings of this study demonstrated that social supports provided opportunity for students to evaluate and monitor their progress on the task: two key processes in selfregulated learning. Online multi-stage assignments can extend the social context of a subject and provide opportunities to support students' self-regulation through socially shared student work. Social models accessed through the shared online learning management systems were particularly significant to the students in this study. Additionally, the alignment of face-to-face social supports with the assignment content and timing was also significant in supporting students' self-regulation. The findings of the study demonstrated that the combination of both face-to-face and online social supports provided a broader range of social supports available to students (Case B).

\subsection{Challenges that social cues did not support}

Four students experienced motivational challenges (Table 1). Reporting a decline in motivation related to the repetitive nature the task design and corresponding low value assigned to the task. Research has suggested that social modelling can boost students' motivation and self-efficacy through a belief that they too can succeed in the task (Schunck \& Zimmerman, 2003). Yet, these students did not engage with any social cues to address motivational challenges. Similarly, seven students described the intermittent timing of post submissions as a challenge to their ability to manage time around the task. Students did not engage with social cues to address such a challenge. These findings draw attention to: 1) aspects of the learning design, including repetition and intermittent timing of task deadlines that hindered task engagement for a small subset of students; and 2) the undermining role that low motivation can have on self-regulatory processes. This suggests implications for the design of multi-stage assignments. For many students the multi-stage nature of the task supported regulation when faced with a challenge, suggesting that repetition is a valuable design component. Self-regulated learning research suggests that task value or purpose, feedback and self-efficacy may support student motivation (Schunck \& Zimmerman, 2003). Thus, making clearer connections to task purpose and providing formative feedback throughout the task period could better support students' engagement across the task period.

Socio-cognitive models of self-regulation illustrate how academic competence can develop from social sources, including models, description, guidance and feedback, and move to self-sources as students develop self-regulation (Schunk, 2009). The findings from this study suggest that online multi-stage assignment designs can support students' regulation and confidence. The shared nature of the online task space for students in Cases A and B, in combination with the repetition of the task provided students with a variety of social cues to support learning and the space to enact feedback and develop academic competence. Additionally, the face-to-face learning design aligned with the 
online task facilitated students' academic development and self-regulation through the provision of strategies, discussion of domain knowledge, connection to the task purpose along with the space to practice and refine learning across multiple iterations.

In practice, students' engagement with the multi-stage assignments in online and face-toface contexts revealed processes of both self-regulation and co-regulation between students. Similarly, researchers have suggested it is possible to observe multiple forms of regulation, recognising the different ways that self and social inform the regulation of learning to occur (Hadwin \& Järvelä, 2011; Hadwin \& Oshige, 2011; Volet, Summers, \& Thurman, 2009).

\section{Implications}

The findings presented in this paper suggest a number of practical implications for the design of online multi-stage assignments and learning environments (both online and offline) to support university students' self-regulated learning. The challenges reported across the three cases tell us that task understanding continues to be a significant challenge for students, which is perhaps exacerbated in less familiar and prescribed online assignments. This suggests direct implications for how such online multi-stage assignments are designed, particularly how they are defined by the teacher(s) and how they are communicated to students, including both written and verbal instructions (Butler $\&$ Cartier, 2004). Online tasks require a more considered approach that does not assume student understanding of the online genre and makes implicit teacher or disciplinary expectations explicit to students. Furthermore, the open-ended design of such tasks requires scaffolds to support students. The challenges students experienced and social cues they engaged with when faced with a challenge while completing the multi-stage assignments examined in this study suggest that:

- Social models, created through sharing students' assignment work online, can act as useful scaffold for supporting students' self-regulation and engagement in multi-stage assignments.

- Multi-stage assignment design affords students the opportunity for rehearsal by repeating the activity over the task period. This, together with social models, supported students to reflect, monitor and evaluate: key processes of SRL, while working on an assignment, an example of assessment for learning (Butler \& Cartier, 2004).

\section{Limitations}

It is important to acknowledge the limitations of the study. Firstly, the findings presented feature a relatively small data set of 34 students across three universities. This limits the generalisability of the findings. Nonetheless the findings suggest some promising aspects of the online social learning environment that can support students' self-regulated learning, for which there is scope for more research. Secondly, the study relied on the self-reports of processes of SRL associated with overcoming challenges. This may be problematic due to the internalisation or automaticity of many cognitive processes (Butler, 2002), posing potential difficulties to self-identify and articulate. We 
acknowledge that no single methodology can accurately and completely capture these complex processes. While self-report methods may not be the most accurate method, the rich interview data presented was the most appropriate method in this instance to explore how and why students encountered challenges and attempted to overcome these using social supports.

While students' cognition occurs unconsciously a challenge can shift thinking from occurring implicitly to explicit cognition and metacognition in an attempt to address difficulties and complete the task (Winne, 2011). This sequence of events provides a rich area for the investigation of the processes of self-regulated learning, when the oftenimplicit processes of cognition become conscious to students. Thus, the challenges identified in this study, in particular the variation in students' challenges associated with task understanding warrants further investigation with a larger data set. This qualitative study also found that when students could view peers work online they were able to use the online space as a social support to overcome challenges and complete the task. A larger mixed-method analysis, including log-file data, of such a phenomenon is of interest to the research team. In addition, we did not report on the outcomes of the assignment tasks. Hence, an exploration of the outcomes of students who use social supports to overcome challenges is also of interest to the research team.

\section{Conclusion}

This paper presented an investigation of three online multi-stage assessments delivered at two Australian universities. The findings present evidence about the types of challenges students experienced and the specific social cues that supported students' self-regulation to complete the task. Knowledge of the task challenges posed the most significant problem for students in this study. Students described variation in this type of challenge including unclear task understanding, lack of experience with task form, and confusion about how to approach the task.

The shared online design extended the social context of the unit and assignment task, providing additional and effective social cues for students' task understanding, domain knowledge, monitoring of task progress and performance within the teaching and learning context. Assignment alignment with face-to-face learning experiences also provided teachers with the opportunity to scaffold students' regulation. Finally, in Case A and B the shared online multi-stage element of the assignment design supported students by affording them the space to monitor and evaluate during production and repeat the process to close the gap between their current and expected performance. In Case C, where the online space did not afford sharing, this process occurred in face-to- face classes. The implications of such findings highlight the important role of social cues in online and offline spaces in supporting students' SRL and academic development. The study highlights opportunities for further research investigating challenges experienced by students completing online assessments over a period of time and the role of selfregulation, along a continuum of self and social in overcoming such challenges. 


\section{Acknowledgments}

The research presented is part of the larger research project University learning in the digital age: Investigating how students learn online (DP140100406) funded by the Australian Government through the Australian Research Council. 


\section{References}

Boud, D. (2000). Sustainable Assessment: Rethinking assessment for the learning society. Studies in Continuing Education, 22(2), 151-167. https://doi.org/10.1080/713695728

Brown, G. T. L., Peterson, E. R., \& Yao, E. S. (2016). Student conceptions of feedback: Impact on self-regulation, self-efficacy, and academic achievement. British Journal of Educational Psychology, 86(4), 606-629. https://doi.org/10.1111/bjep.12126

Butler, D., \& Cartier, S. (2004). Promoting effective task interpretation as an important work habit: A key to successful teaching and learning. The Teachers College Record, 106(9), 1729-1758.

Butler, D. L. (2002). Qualitative Approaches to Investigating Self-Regulated Learning: Contributions and Challenges. Educational Psychologist, 37(1), 59-63. https://doi.org/10.1207/S15326985EP3701_7

Cheng, G., \& Chau, J. (2013). Exploring the relationship between students' self-regulated learning ability and their ePortfolio achievement. The Internet and Higher Education, 17, 9-15. https://doi.org/10.1016/j.iheduc.2012.09.005

English, M. C. , \& Kitsantas, A. (2013). Supporting Student Self-Regulated Learning in Problem- and Project-Based Learning. Interdisciplinary Journal of ProblemBased Learning, 7(2). Available at: https://doi.org/10.7771/1541-5015.1339

Hadwin, A. F., \& Järvelä, S. (2011). Introduction to a special issue on social aspects of self-regulated learning: Where social and self meet in the strategic regulation of learning. Teachers College Record, 113(2), 235-239.

Hadwin, A., \& Oshige, M. (2011). Self-regulation, coregulation, and socially shared regulation: Exploring perspectives of social in self-regulated learning theory. Teachers College Record, 113(2), 240-264.

Hadwin, Allyson F., Oshige, M., Gress, C. L. Z., \& Winne, P. H. (2010). Innovative ways for using gStudy to orchestrate and research social aspects of self-regulated learning. Computers in Human Behavior, 26(5), 794-805. https://doi.org/10.1016/j.chb.2007.06.007

Herrington, J., Reeves, T. C., Oliver, R., \& Woo, Y. (2004). Designing authentic activities in web-based courses. Journal of Computing in Higher Education, 16(1), 3-29. 
Jonassen, D. H., \& Kim, B. (2010). Arguing to learn and learning to argue: design justifications and guidelines. Educational Technology Research and Development, 58(4), 439-457. https://doi.org/10.1007/s11423-009-9143-8

Karabenick, S., \& Knapp, J. (1991). Relationship of academic help seeking to the use of learning strategies and other instrumental achievement behavior in college students. Journal of Educational Psychology, 83, 221-230.

Kim, M. C., \& Hannafin, M. J. (2011). Scaffolding problem solving in technologyenhanced learning environments (TELEs): Bridging research and theory with practice. Computers \& Education, 56(2), 403-417. https://doi.org/10.1016/j.compedu.2010.08.024

Kornell, N., \& Bjork, R. A. (2007). The promise and perils of self-regulated study. Psychonomic Bulletin \& Review, 14(2), 219-224.

Laurillard, D. (2009). The pedagogical challenges to collaborative technologies. International Journal of Computer-Supported Collaborative Learning, 4(1), 5-20.

Lin, J.-W. (2018). Effects of an online team project-based learning environment with group awareness and peer evaluation on socially shared regulation of learning and self-regulated learning. Behaviour \& Information Technology, 37(5), 445-461. https://doi.org/10.1080/0144929X.2018.1451558

Lockyer, L., Patterson, J., \& Harper, B. (2001). ICT in higher education: Evaluating outcomes for health education. Journal of Computer Assisted Learning, 17(3), $275-283$.

Nicol, D. J., \& Macfarlane-Dick, D. (2006). Formative assessment and self-regulated learning: a model and seven principles of good feedback practice. Studies in Higher Education, 31(2), 199-218. https://doi.org/10.1080/03075070600572090

Oshige, M. (2009). Exploring Task Understanding in Self-regulated Learning: Task Understanding as a Predictor of Academic Success in Undergraduate Students (Master of Arts). University of Victoria, Victoria.

Rivera-Reyes, P., Lawanto, O., \& Pate, M. L. (2017). Students' Task Interpretation and Conceptual Understanding in an Electronics Laboratory. IEEE Transactions on Education, 1-8. https://doi.org/10.1109/TE.2017.2689723

Schunck, D., \& Zimmerman, B. (2003). Self-Regulation and Learning. In W. Reynolds, G. Miller, \& I. Weiner (Eds.), Handbook of Psychology: Volume 7 Educational psychology (pp. 59-78). Hoboken, NJ: John Wiley \& Sons. 
Schunk, D. (2009). Social cognitive theory and self regulated learning. In B. J.

Zimmerman \& D. Schunk (Eds.), Self-Regulated learning and academic achievement: Theoretical perspectives (2nd ed., pp. 125-151). New York: Routledge.

Sweller, J. (2016). Story of a Research Program. Education Review//Reseñas Educativas, 23. Retrieved from http://edrev.asu.edu/edrev/index.php/ER/article/viewFile/2025/545

Volet, S., Summers, M., \& Thurman, J. (2009). High-level co-regulation in collaborative learning: How does it emerge and how is it sustained? Learning and Instruction, 19(2), 128-143. https://doi.org/10.1016/j.learninstruc.2008.03.001

Whipp, J. L., \& Chiarelli, S. (2004). Self-regulation in a web-based course: A case study. Educational Technology Research and Development, 52(4), 5-21. https://doi.org/10.1007/BF02504714

Winne, P. (2011). A cognitive and metacognitive analysis of self-regulated learning. In Barry J. Zimmerman \& D. H. Schunk (Eds.), Handbook of self-regulation of learning and performance (pp. 1-32). Routledge.

Winne, P. H., \& Hadwin, A. (1998). Studying as self-regulated learning. In D. Hacker, J. Dunlosky, \& A. Graesser (Eds.), Metacognition in Educational Theory and Practice (pp. 277-304). Mahwah, NJ: Lawrence Erlbaum.

Zimmerman, Barry J., \& Schunk, D. H. (2011). Self-regulated learning and performance: An introduction and an overview. In Handbook of self-regulated learning and performance. New York: Routledge. 